\title{
UNA PINTURA DEL MAESTRO DEL PAPAGAYO EN EL MUSEO MAYER VAN DEN BERGH DE AMBERES
}

En reciente visita al Museo Mayer Van den Bergh de la ciudad de Amberes (2002), hemos podido reconocer un ejemplo más de una pintura del Maestro del Papagayo, con atribución al Maestro de las Medias Figuras [48,4×38 cm, Fig. 1]. No es sorprendente esta confusión, pues el Maestro del Papagayo - que recibe su apelación por el pájaro exótico que acompaña a la Virgen con Niño en sus tablas más conocidas ${ }^{1}$ - está en el mismo circuito estético y social que el de las Medias Figuras ${ }^{2}$, y habitualmente se confunde con él.

La primera atribución de esta tabla al Maestro de las Medias Figuras fue formulada por Winckler en $1904{ }^{3}$ y M. Genaille la incluyó recientemente en su estudio específico sobre este maestro, considerándola como una de sus obras «más significativas y bellas» ${ }^{4}$. La pintura procede del conde de La Rochefoucauld, y fue adquirida en París en la colección del barón de Thornitz en 1900. Desde entonces se mantiene en los catálogos del museo Mayer con la misma atribución ${ }^{5}$.

La silueta de la joven, vista a media altura, se recorta sobre un fondo oscuro. Colocada de tres cuartos de perfil, la cabeza ligeramente inclinada, los ojos bajos y atentos a la lectura de un libro que sostiene con delicadeza entre los dedos de sus manos, la joven permanece ensimismada en sus pensamientos, olvidando la presencia del espectador. A su derecha, un vaso de cerámica ornada con motivos florales estilizados reposa sobre una mesilla con patas de ricos grotescos y volutas. Viste un traje de terciopelo con amplio escote cuadrado hasta los hombros, sobre el que destacan dos finas y largas cadenas entrecruzadas. Lleva un exquisito tocado adornado con perlas sobre su cabello recogido y graciosamente ondulado.

La confusión con el Maestro de las Medias Figuras es comprensible, no sólo por la utilización de esquemas que son similares, sino porque el sentimiento de estas jóvenes es el mismo. Es pues de suponer que ambos comparten sus fuentes de inspiración. Pero la confusión no sólo alcanza a estos dos maestros, encontramos también composiciones con el mismo esquema en Isembrant y Benson. Es el reflejo de un sentimiento común en el circuito de Brujas, que corresponde con el clima del renacimiento nórdico, en cuyas cortes sabemos se creó un delicado ambiente de integración de las jóvenes en la cultura. La naturaleza de estas pinturas está cargada de gracia mundana. El vaso de ungüentos que siempre se añade, ya sea de cerámica o, más comúnmente, de orfebrería, explica el título de Magdalena que se ha dado a este tipo de representación. Pero este tema no es más que un pretexto para incitar el clima de encanto ju-

\footnotetext{
' Virgen con Niño de la Pannwitz Collection, Feist Collection y mercado de arte en Viena, 1938, $(110 \times 70 \mathrm{~cm})$. [Véase Friedländer, M., Early Netherlandish Painting, XII, 1975, p. 20, figs. 210A, 210B].

${ }^{2}$ A propósito del Maestro de las Medias Figuras véase: Justi, K., «Altfländische Bilden in Spanien und Portugal», Zeitschrift fur Bild. Kunt, XXI, pp. 93-98, 133-140; Wickhoff, F., «Die weiblichen Halbfiguren aus der Zeit und Umgebung von Frankreich», Jahrbuch der Kunsthistorischen Sammlungen des allerhöchsten Kaisehauses, XXII, 1901, p. 190; Benesch, O., «The name of the Master of Half Lengths», Gazette des Beaux-Arts, 1943, I, pp. 269-282; Rostworowski, M., «Le Maître des femmes a mi-corps», Bulletyn Historii Sztuki, 22, 1960, p. 371-377; Hernández Perera, J., «Museo español del Maestro de las Medias Figuras», Goya, 49, Madrid, 1962, pp. 2-11; Bergmans, S., «Le Maître des demi-figures de femmes», Le siècle de Brueghel, Cat. Exp. Bruselas, 1953, pp. 170-172; Marlier, G., «Wer ist der Meister der weiblichen Halbfiguren ?», Gemälde bedeutender Niederländischer Meister des 17 Jahrhunderts, Galería Friedeicke Palamar, Viena , 1966, p. 15-20; Kokh, Joachim Patenir, Princeton, 1968, pp. 56-65; Friedländer, M., Early Nederländish Painting, XII, Leiden-Bruselas, 1975, pp. 18-21; Díaz Padrón, M., «Nuevas Pinturas del Maestro de las Medias Figuras», Archivo español de Arte, 1980, pp. 169 y ss; Idem, «Pintores flamencos del xvi: Tablas del Maestro de las Medias Figuras identificadas en España, Caracas y Santiago de Chile», Archivo Español de Arte, 1982, pp. 273 y ss; Genaille, R, «A propos du Maître des demi-figures féminines», Koninklijk Museum voor Schone Kunsten-Antwerpen Jaarboek, 1985, pp. 137-176.

${ }^{3}$ Winkler, F., Collection du Chevalier Mayer van den Bergh. Catalogue des Tableaux, Amberes, 1904, No. 41; Winckler, Die Altniederland Malerei, Berlin, 1924, p. 382.

${ }^{4}$ Genaille, Op. Cit. 1985, p. 154.

${ }^{5}$ Museum Mayer van den Bergh. Catalogus I, Amberes, 1978, p. 94, №. 361.
}

AEA, LXXVI, 2003, 304, pp. 407 a 436 


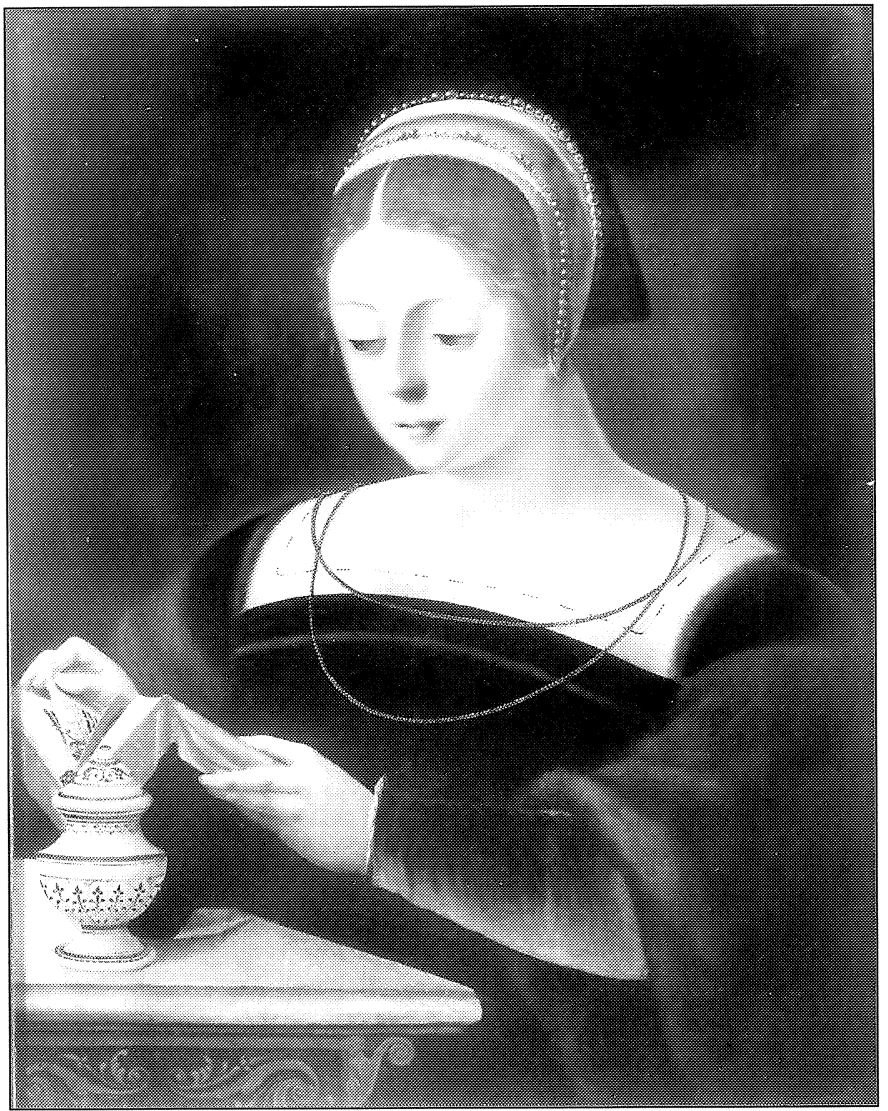

2

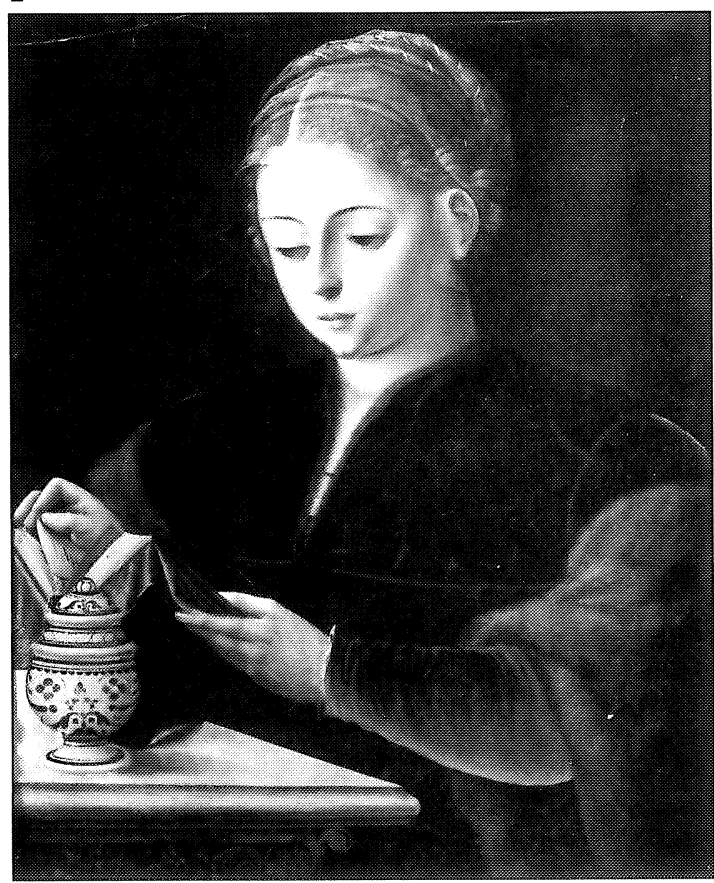

Fig. 1. Maestro del Papagayo, Magdalena leyendo. Amberes, Museo Mayer van de Berg.

Fig. 2. Maestro del Papagayo, Magdalena leyendo. Madrid; colección particular.

Fig. 3. Maestro del Papagayo, Magdalena leyendo. Madrid, colección particular.

AEA, LXXVI, 2003, 304, pp. 407 a 436 
venil de las jóvenes refinadas de la corte de Margarita de Austria, con protagonismo de la mujer, promulgadora de valores de belleza, encanto, refinamiento, exquisitez y amor a la lectura. La indumentaria corresponde con la moda de la época. Se hace énfasis en la hermosura y en la riqueza de las ropas, reflejo de la situación privilegiada que permitía a estas féminas dedicarse a pasatiempos instructivos. Muchos modelos están estereotipados, pero la observación de rasgos individualizados en algunas de ellas, permite pensar que en muchos casos se tratara de retratos. Marlier explicó así la profileración de estas Magdalenas, considerándolas el pendant femenino de los numersos San Jerónimo en su estudio que decoraban los gabinetes de los clérigos y eruditos ${ }^{6}$. Friedländer mencionó en cambio un pasaje de la Vie des Dames Galantes de Brantôme, que se refiere a pinturas flamencas de jóvenes y hermosas mujeres, que en Francia se colocaban encima de la chimenea en interiores y tabernas ${ }^{7}$.

La imagen de estas jovencitas etéreas, que Marlier comparó con «flores de invernadero» 8 , arrastra los signos de exquisitez que se transmite en la escuela de Brujas desde Gerard David. Joos van Cleve, Ysembrant, Provost y Van Orley compartieron hacia 1525 esta aficion por las bellas figuras femeninas llenas de gracia y encanto.

Nos es factible reconocer aquí la personalidad del Maestro del Papagayo, no sólo por la presencia de pormenores diferenciadores de su estilo, sino por la comparación con otras obras conocidas y atribuidas al maestro, donde se repite el mismo modelo. El Maestro de las Medias Figuras utiliza los mismos esquemas y recursos, pero el ideal femenino del Maestro del Papagayo responde a unos prototipos más tiernos, dulces a la vez que llenos. El cuello es más corto y macizo y la cabeza más voluminosa. Los rostros son ligeramente más anchos, la nariz más corta y regular, y la boca más sensual, con las comisuras de los labios ligeramente levantadas. Los ojos hacia abajo son muy característicos. La línea recta y cortante del párpado superior es para nosotros un signo distintivo respecto al diseño más ondulado en el Maestro de las Medias Figuras, que pinta un párpado más redondo. Conforman los cabellos bucles más variados y sueltos, en ocasiones con mechones que caen hacia los hombros. Los dedos son más cortos y carnosos, están matizados en su anatomía, con una conformación casi triangular, terminándose en uñas grandes y ovaladas.

Los matices lumínicos del Papagayo son más intensos y variados, conformando con calidez las sombras del rostro. Aquí el foco de luz viene de la izquierda, dejando el resto en penumbra, para destacar así el protagonismo del rostro, del que no distraen siquiera los ricos pormenores de las ropas y el vaso. El Maestro de las Medias Figuras gusta de fondos más variados, representando en ellos elementos de un interior para distraer la atención; mientras que el Papagayo prefiere dejarlos en una atmósfera de penumbra. La silueta de la joven se recorta así sobre el fondo oscuro, siendo fundamental el efecto de iluminación y claroscuro para el clima de emotividad de estas composiciones. La intensidad cromática en el Maestro del Papagayo es mayor. La luz que incide sobre las pieles y el terciopelo acentúa con sus reflejos las calidades de las cosas. Su ejecución es generalmente más lisa y esmaltada y más rica en veladuras. Vimos la capa pictórica afectada por barridos que ensombrecían la apreciación de estos valores; pero una segunda visita al museo en agosto de 2003 nos permitió constatar que la restauración llevada a cabo recientemente ha devuelto a la pintura todo su esplendor.

El rostro es el mismo en dos pinturas conocidas en colección privada de Madrid [Fig. 2] y colección Boer de Amsterdam, que podríamos considerar como replicas ${ }^{9}$. Sin embargo, en

\footnotetext{
${ }^{6}$ Marlier, G., «Ambrosius Benson et le thème de la Sybille», Bulletin du Musée de Varsovie, 1963, n², pp. $56-58$.

${ }^{7}$ Friedländer, M., Early Netherlandish Painting, XII, 1975, p. 19.

${ }^{8}$ Marlier, Op. cit., p. 200.

${ }^{9}$ Véase Díaz Padrón, M., «Nuevas pinturas del Maestro del Papagayo identificadas en colecciones españolas y extranjeras», Archivo Español de Arte, LVII, 22, figs. 20 y 23.
} 
estas dos pinturas el vestido cubre el pecho y los hombros con total recato. La pintura que tratamos deja un escote abierto con dos cadenas de oro y parte de los hombros descubiertos. La única difrencia ostensible consiste en la indumentaria. Pero esta indumentaria, con sutil encaje transparente que bordea el escote rematado en piel, es idéntica en otra versión recientemente identificada ${ }^{10}$ que reproducimos aquí [Fig. 3], donde tanto el rostro como las manos son los mismos. Difiere en cambio por la mayor riqueza y ostentación del vaso de orfebrería y por la disposición de las cadenas en el escote.

La tabla del Museo Mayer van den Bergh presenta pocas diferencias respecto a las obras conocidas del pintor. Como ocurre parcialmente en la versión de Madrid que reproducimos, aquí la cofia oculta por completo la oreja, que suele tener en otras pinturas un diseño muy particular, un aspecto carnoso que las diferencia de las más esquemáticas del Maestro de las Medias Figuras. El preciso diseño de grotescos renacentistas de la mesa se repite en la tabla de Madrid y en otras versiones que conocemos. Encontramos rostros muy similares en la Virgen con el Niño de la colección Goldsmit ${ }^{11}$. Sin duda, es el modelo más noble de los que vemos en él, repetido en la Piedad de colección privada de Madrid y en la Virgen y el Niño de la New York Art Association ${ }^{12}$.

Poco se sabe sobre los orígenes y la formación de este maestro Un retrato fechado en $1524{ }^{13}$ permite situarlo cronológicamente pero ningún dato se conoce sobre su biografía. A juzgar por las tablas con este tema que han llegado hasta nosotros, debía proporcionarle éxito y lo trató con asiduidad. Friedländer sugiere la posibilidad de que estos maestros, procedentes de la escuela de Brujas, se trasladaran a Amberes a principios del siglo xvI, llamados por un comercio más floreciente, donde este tipo de trabajo especializado, a la vez que de calidad, era idóneo para la exportación. Esto explicaría el gran número de réplicas que ha llegado hasta nosotros, y la abundancia de sus obras en España, donde se ha localizado buena parte de su producción de contenido religioso ${ }^{14}$.

JAHel SANZSALAZAR

${ }^{10}$ Díaz Padrón, M., «Tres nuevas tablas de la Magdalena del Maestro del Papagayo idetificadas» (en prensa).

"Véase Díaz Padrón, Op. cit. 1984, fig. 22.

${ }^{12}$ Véase $O p$. cit. supra, figs. 13 y 24.

${ }^{13}$ Se trata de un retrato femenino $(55 \times 39,5 \mathrm{~cm})$ fechado en el marco que figuró en venta Fischer de Lucerna, 2-5-1937, No. 2228. [Véase Friedländer, Op. cit. 1975, fig. 210C].

${ }^{14}$ Díaz Padrón, M., «Una tabla del Maestro del Papagayo atribuida a Heinrich Aldegrever en el Museo del Prado», Boletín del Museo del Prado, 1983, V, p. 97; Idem, Op. cit. 1984, pp. 257-276; Idem, «Una tabla del Maestro del Papagayo desconocida del Museo de Bellas Artes de Bilbao», Boletín de la Real Academis de Bellas Artes de San Fernando, No. 62, 1986, pp. 157-160.

AEA, LXXVI, 2003, 304, pp. 407 a 436 